\title{
Metodologia e Modelos Econômicos
}

\author{
Carolina Miranda Cavalcante
}

\begin{abstract}
In this paper, we illustrate some important concepts of philosophy of science through the exposure of two macroeconomic models fairly simple, classical and Keynesian, presented in introductory macroeconomic courses. Concepts worked in philosophy of science as the hypothetical-deductive model, the symmetry thesis, the idea of Kuhnian paradigm, Lakatosian scientific research program, as well as those proposed by Lawson in the field of critical realism, are sought and identified in these macroeconomic models as a way to show that the study of methodology is fundamental to the understanding of the scientific theories — the raw material of social science.
\end{abstract}

Keywords: Hypothetical-deductive model; macroeconomic models; relativism; instrumentalism; critical realism.

\section{Introdução}

O estudo de filosofia da ciência aparece imediatamente para o estudante de economia como um estudo sem conexão com o conjunto de saberes exigido de um economista. Entretanto, precisamos entender em que consiste a profissão do economista, afinal, o que é ser economista? O economista é antes de tudo um cientista social, que, no exercício de sua profissão, terá como campo de aplicação de suas teorias a sociedade. Para além da responsabilidade envolvida nesta tarefa, o economista deve ter consciência das ideias que veicula, não apenas de suas consequências, mas de sua origem, ou seja, qual a imagem de mundo que se projeta através dos pressupostos básicos de uma teoria econômica? Se uma teoria científica tem o potencial de permear as crenças do cotidiano, podendo se tornar parte da significação do mundo por parte dos sujeitos de modo a orientar seu modo de agir em sociedade, então, verifica-se o papel essencial dessa visão de mundo que toda teoria científica veicula. ${ }^{1}$

Nos manuais introdutórios de economia, normalmente inicia-se a apresentação do estudo da economia com a questão acerca do que é o economista e qual é o seu modo de pensar. Vejamos como Mankiw apresenta o método do economista.

Da mesma forma que o físico começa a análise da queda da bolinha de gude afastando a existência do atrito, os economistas afastam muitos dos pormenores da economia que são irrelevantes para a questão em pauta. Todos os modelos — na física, na biologia ou na economia — simplificam a realidade para melhorar a sua compreensão. (Mankiw 1999, p.23)

Principia 18(2): 187-208 (2014).

Published by NEL — Epistemology and Logic Research Group, Federal University of Santa Catarina (UFSC), Brazil. 
Este é o método utilizado pelo mainstream em economia, no entanto, não é o único método e está longe de ser o método da Economia. Afirmá-lo como tal seria negar um dos resultados mais perturbadores após a falência do projeto lógicopositivista, a saber, não há consenso com relação ao que seja, de fato, o método científico correto. Uma das ideias veiculadas nos modernos debates em filosofia da ciência faz uma defesa incondicional de uma pluralidade de métodos, cujo fundamento é o reconhecimento do caráter histórico das teorias científicas. A partir dessa perspectiva, a asserção de que o método da Economia busca construir modelos simplificadores da realidade, em que hipóteses irrealistas são colocadas na base desses modelos, revela uma negligência acerca da concepção de ciência veiculada através de tal asserção. De modo mais claro, a ideia que Mankiw entretém acerca do empreendimento científico é justamente a defendida por Friedman (1981) — o instrumentalismo. Rossetti adota uma abordagem mais plural, na esteira dos desenvolvimentos kuhniano e lakatosiano no campo da filosofia da ciência na década de 1970.

(...) cada corrente de pensamento econômico enxerga a realidade sob ângulos diferenciados, a partir dos quais elabora suas concepções, estabelece seus conceitos e formata seus modelos. E tem mais: ao longo do tempo, as instituições econômicas e as concepções político-ideológicas se modificam. Torna-se geralmente maior a complexidade do processo econômico. Surgem novas preocupações. E evolui, decorrentemente, o conceito de economia. (Rossetti 2000, p.45-6)

Apesar da concepção de ciência econômica de Rossetti ter sido contraposta à de Mankiw, isso não quer dizer que o pluralismo teórico e metodológico seja a solução incontroversa para as desventuras do positivismo lógico. De fato, não é. E também não é uma alternativa ao método instrumental que, segundo Duayer et alii (2001), consiste antes no resultado previsível decorrente das desventuras do projeto lógicopositivista. Com essa rápida incursão em dois manuais introdutórios de economia, pode-se observar que determinadas concepções científicas refletem debates que são travados no campo da metodologia econômica, apontando, assim, para a importância do estudo de questões metodológicas. Logo, o que se pretende indicar é a essencialidade do reconhecimento de que toda teoria econômica pressupõe uma ontologia, uma visão de mundo, e orienta-se de acordo com um método, que tem suas raízes no campo da filosofia da ciência. Desse modo, pode-se entender como comunidades científicas diversas compreendem um objeto de estudo, que lhes é comum, de maneira diferente.

A afirmação de uma pluralidade teórica e metodológica suscita uma questão extremamente relevante - se várias teorias concorrem para a explicação do mesmo mundo, como escolher uma delas e/ou explicar a superioridade de uma comunidade científica frente às demais? Kuhn e Lakatos, ao afirmarem o caráter histórico e social do conhecimento científico, lançam as bases do relativismo epistemológico, 
respondendo a essa questão com a proposição de um relativismo ontológico. Tal relativismo ontológico consiste na postulação de que as hipóteses fundamentais das teorias científicas são irrefutáveis, portanto, não há qualquer critério racional para escolha entre teorias. A superioridade teórica é, portanto, explicada através da fé da comunidade científica em tal conjunto de hipóteses fundamentais, segundo Kuhn, ou, de acordo com Lakatos, essa superioridade é relativa à capacidade das teorias em produzir previsões acuradas acerca de determinados fenômenos da realidade.

Uma visão alternativa, que tem ganhando espaço nos debates metodológicos, constitui o realismo crítico, em que seus principais autores são Roy Bhaskar e Tony Lawson. A proposta central dessa corrente filosófica é a restauração da ontologia. Tal proposta consiste na asserção de que toda teoria, antes de qualquer postulação científica, significa o mundo. Por conseguinte, as hipóteses fundamentais das teorias científicas, que produzem essa imagem do mundo, devem ser criticamente investigadas, pois somente dessa maneira uma racionalidade julgamental seria possível. Assim, o realismo crítico se aproxima da proposta de Kuhn e Lakatos apenas na questão concernente ao reconhecimento do caráter histórico do conhecimento científico - relativismo epistemológico — , mas desta se distancia quanto ao papel da ontologia na crítica teórica e filosófica. Numa visão crítico-realista do empreendimento científico, a explicitação da ontologia é fundamental para que um critério racional de escolha entre teorias possa ser obtido, pois somente a realidade pode nos fornecer um campo de teste válido, e a comparação entre teorias somente pode se efetivar por intermédio do confronto das visões de mundo produzidas por teorias diversas.

No que segue, pretendemos apresentar dois modelos macroeconômicos - modelo clássico e modelo keynesiano - indicando como os conceitos empregados no campo da metodologia econômica podem ser entendidos através da estrutura desses modelos. Na seção primeira apresentamos o conceito de modelo hipotético-dedutivo e lei científica do tipo covering-law. A seção segunda é reservada à exposição do modelo clássico simples, como exemplificação dos conceitos desenvolvidos na seção anterior. Na seção terceira, a proposta metodológica de Kuhn e Lakatos é apresentada, sendo os conceitos de programa de pesquisa científico (PPC) e paradigma ilustrados a partir do modelo keynesiano. Uma posição crítica em relação ao relativismo kuhniano e lakatosiano, bem como a uma concepção instrumental de ciência, é apresentada na seção quarta a partir das contribuições de Bhaskar $(1997,1998)$ e Lawson $(1997,2003,2015)$ no campo do realismo crítico.

\section{Conceituando o modelo hipotético-dedutivo (tese da simetria)}

O modelo hipotético-dedutivo (modelo $H-D$ ) pode ser conceituado como uma estrutura teórica, que comporta hipóteses fundamentais e axiomas, que se referem ou 
não a entidades observáveis. Somente a teoria, como um todo, pode ser submetida ao teste empírico, seus elementos internos — hipóteses e axiomas — são indiretamente validados, na medida em que o modelo teórico seja empiricamente corroborado.

(...) a estrutura formal de uma teoria é nada mais que um cálculo mecânico, ou um sistema hipotético-dedutivo. Uma teoria contém axiomas, ou sentenças primitivas, e teoremas, ou declarações derivativas. Os axiomas devem se referir tanto a observáveis quanto a entidades teoréticas. ${ }^{2}$ (Caldwell 1982, p.25)

Essas hipóteses fundamentais são asserções sobre eventos da realidade. Parte-se da ideia de que o mundo é povoado de eventos econômicos e a tarefa da Economia é capturá-los no interior de modelos teóricos. Para que essa tarefa seja realizada, faz-se uso de abstrações que se cristalizam nas hipóteses fundamentais do modelo. O objetivo do método científico é produzir uma imagem do mundo que permita ao sujeito cognoscente interpretar os fenômenos da realidade. Nesse sentido, uma teoria científica não pode ser uma cópia perfeita do mundo, pois a realidade efetiva é diferente da realidade pensada, da visão de mundo. No escopo do modelo $H-D$, essas abstrações possuem um caráter simplificador de relações reais presentes no mundo, que são capturadas por meio de um método dedutivo ou indutivo.
A metodologia da elaboração científica, em sua estrutura fundamental, bus- ca, como primeiro passo, observar sistematicamente a realidade. Depois, ela- borar modelos simplificados que a reproduzam, que identifiquem relações de causas e efeitos e que interpretem os mais variados eventos e seus desdo- bramentos. No processo de elaboração, basicamente, recorre-se a duas abor- dagens distintas, ainda que complementares: a indução e a dedução. Assim, em sua acepção mais simples, as bases sobre as quais se constrói o conhe- cimento científico constituem-se, preliminarmente, de processos descritivos que conduzam ao reconhecimento da realidade e, subseqüentemente, de duas abordagens metodológicas distintas, embora complementares, a indu- tiva e a dedutiva. (Rossetti 2000, p.58)

O método dedutivo consiste na apreensão de elementos da realidade através de um processo de introspecção do sujeito cognoscente, enquanto o método indutivo utiliza-se de fatos observados na realidade para produzir conhecimentos relevantes acerca do mundo.

Os princípios que procuram explicar o comportamento racional dos indivíduos na escolha de padrões de consumo que maximizem sua satisfação são, geralmente, derivações do método dedutivo. Já as relações funcionais de dependência entre, por exemplo, a renda e o consumo da sociedade como um todo resultam da aplicação convencional do método indutivo sobre séries de dados sistematicamente levantados. (Rossetti 2000, p.59)

Principia 18(2): 187-208 (2014). 
Assim, pode-se afirmar que o método dedutivo busca conceituar um elemento de análise, como o consumidor, por exemplo, definido pela teoria microeconômica como um agente racional maximizador de sua utilidade, em que, no processo de obtenção de sua satisfação individual, faz escolhas entre meios alternativos para o alcance de finalidades, ou desejos, ilimitados. Nessa conhecida definição de ciência econômica de Lionel Robbins, todas as relações econômicas podem ser explicadas em termos da compreensão das decisões individuais de alocação de recursos escassos. Deste modo, o consumidor é elevado à categoria central de análise da teoria microeconômica, cuja apreensão ocorre através do uso de um método dedutivo, posto que nenhuma evidência empírica pode ser produzida comprovando ou não tal racionalidade atribuída ao consumidor. A tradicional abordagem dos manuais de economia aponta a necessidade de se complementar o método dedutivo da análise econômica com o método indutivo, visto que os fatos empíricos são importantes instâncias de teste de teorias econômicas. Para que seja possível testar empiricamente teorias científicas, utiliza-se um instrumental econométrico, expressão do amplo uso de elementos estatísticos e matemáticos nos modelos econômicos. ${ }^{3}$ Cabe ainda acrescentar que, numa concepção instrumental de ciência, a realidade dos pressupostos das teorias científicas é irrelevante, pois o que importa é a capacidade preditiva de tais teorias, de modo que a validade empírica de uma teoria não implica que seus

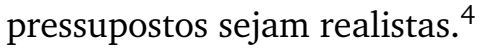

Em sua apreciação crítica dos métodos ortodoxos aplicados em Economia, identificando-os sob a denominação de dedutivismo, Lawson (1997) explicita a filiação de tais métodos a uma visão de mundo, ou ontologia, de eventos atomísticos, que concebe lei científica como conjunção constante de eventos. Lawson aponta que a ontologia pressuposta pelo dedutivismo implica, necessariamente, métodos de investigação científica dedutivistas e indutivistas, pois num mundo composto de eventos atomísticos pode-se apenas estabelecer correlações entre os fatos econômicos, não uma explicação objetiva, que possa capturar relações reais presentes no mundo. Uma apreciação crítica mais detalhada do dedutivismo pode ser encontrada em Lawson (1997). Aqui se pretende apenas tornar mais explícita a concepção de mundo pressuposta pelas teorias econômicas que ilustram o modelo $H-D$ e as leis científicas como conjunção constante de eventos ou covering-law, consistentes num conjunto de condições iniciais e pelo menos uma lei geral, pressupondo ainda uma simetria entre explicação e predição — a tese da simetria.

Veremos, nas seções seguintes, como essa modalidade de construção teórica aparece nas teorias econômicas, conforme veiculadas nos manuais de economia. Embora estejamos tratando apenas das teorias econômicas apresentadas nos manuais de economia, não devemos deixar de notar que essa modalidade de construção teórica implicada no modelo $H-D$ também está presente na construção teórica neoclássica mais recente. A eleição das teorias conforme apresentadas nos manuais de economia 
tem por objetivo facilitar a exposição da metodologia subjacente às teorias econômicas neoclássicas, uma vez que, conforme afirma Kuhn, os manuais são a primeira forma de acesso do incipiente estudante a uma ciência, aos seus métodos e à sua visão de mundo. O que se aprenderia para além dos manuais consistira tão somente no refinamento da teoria dos manuais e na história da ciência em questão. Vejamos como as concepções filosóficas aqui expostas aparecem nos modelos macroeconômicos.

\section{Modelo Clássico Simples: um modelo hipotético-dedutivo de explicação científica}

O modelo clássico simples estrutura-se de acordo com o modelo hipotético-dedutivo de explicação científica. Para tal ancora-se em três hipóteses fundamentais: (i) lei de Say; (ii) neutralidade da moeda; (iii) preços e salários flexíveis. Para que se possa visualizar a imagem de mundo projetada por esse modelo teórico, é preciso entender em que consistem suas hipóteses fundamentais.

A lei de Say afirma que toda oferta gera sua demanda, de modo que no fluxo circular da renda não há qualquer vazamento de recursos para outros fins que não o consumo dos bens e serviços produzidos em uma economia. Naturalmente, a criação automática de demanda a partir da oferta pressupõe uma concepção peculiar da moeda. No escopo da interpretação clássica, a moeda apenas é demanda para realizar transações, não possuindo a função de reserva de valor, que é a própria definição de neutralidade da moeda. Não havendo outro motivo para os agentes demandarem moeda que não seja a realização de trocas, decorre daí que tudo que é produzido deve, necessariamente, ser consumido através do uso da renda gerada no processo de produção de bens e serviços. Temos, portanto, que toda oferta, no mundo clássico, gera sua própria demanda. A hipótese de preços e salários flexíveis é importante para o estabelecimento do equilíbrio automático entre oferta e demanda por trabalho no mercado de trabalho. Esse equilíbrio é o coração do modelo, visto que é no encontro das curvas de oferta e demanda por trabalho que o nível de emprego, por conseguinte, de renda, de pleno emprego é estabelecido.

Podemos aqui indicar a visão de mundo que esse modelo pressupõe. No mundo clássico, os agentes são livres para escolher ofertar ou não sua força de trabalho a um dado salário real, podendo sempre encontrar emprego desde que aceitem os salários oferecidos. Deste modo, o desemprego pode apenas ser resultado de uma recusa do agente em aceitar um dado salário real. De maneira mais formal, o desemprego, no mundo clássico, pode apenas ser voluntário, jamais involuntário, pois a hipótese de flexibilidade de preços e salários garante um equilíbrio ao nível do pleno emprego. Outro ponto importante a ser destacado remete à lei de Say, que indica que no

Principia 18(2): 187-208 (2014). 
mundo clássico não há possibilidade de crises de realização, visto que tudo que é ofertado é demandado, condição esta garantida pela hipótese de neutralidade da moeda.

Percebe-se, assim, que o modelo clássico simples fornece um conjunto de hipóteses fundamentais que nos permite explicar uma ampla gama de fatos econômicos. O desemprego, por exemplo, é explicado como resultado de um salário real muito elevado, em que há por um lado um excesso de oferta de trabalho e por outro uma reduzida demanda por trabalho; como salários e preços são flexíveis, o salário real deverá recuar, de maneira a restabelecer o equilíbrio entre oferta e demanda por trabalho. A partir das hipóteses fundamentais do modelo podemos não apenas explicar os fenômenos de interesse, mas também podemos prever comportamentos dos agentes econômicos. Pode-se prever, por exemplo, o que aconteceria na economia se um choque adverso qualquer causasse uma redução na população economicamente ativa (PEA). Essa redução na PEA causaria uma contração no número de trabalhadores, implicando uma contração na oferta de trabalho, elevando salários reais e reduzindo o nível de produto de pleno emprego. A validade do modelo seria avaliada de acordo com sua adequação empírica, ou seja, a teoria é tão boa quanto o grau de precisão de suas previsões. Temos aqui um critério de escolha entre teorias essencialmente instrumental.

Apesar disso, segundo Caldwell (1982), o modelo $H-D$ serviria tanto para realistas como para instrumentalistas. A partir de uma concepção de ciência como a de Lawson (1997), que podemos qualificar como realista transcendental, explicitamos a visão de mundo pressuposta pelo modelo clássico. O critério de validação desse modelo consistiria, portanto, na sua comparação com a realidade mesma, o que, naturalmente, invalidaria tal modelo, visto que no mundo não vigoram as relações econômicas projetadas pelo modelo clássico. Entretanto, de acordo com uma concepção instrumental de ciência, essa irrealidade dos pressupostos clássicos não seria um problema, desde que tal modelo fosse capaz de fornecer previsões acuradas acerca dos eventos econômicos. A solução de Caldwell para esse impasse é o pluralismo metodológico, que acreditamos não ser uma solução válida, pois o discurso científico não pode ser neutro com relação ao método adotado, de modo que a explicitação e a crítica de tal método são fundamentais para a construção de uma filosofia da ciência crítica. Essa última posição é a adotada por Lawson (1997), que será considerado mais atentamente ao final do texto.

\section{Modelo Keynesiano Simples: uma visão de mundo alternativa}

Mankiw (1998) aponta como principal diferença entre o modelo clássico e o modelo keynesiano a hipótese de flexibilidade de preços e salários, adotada pelo primeiro 
e rejeitada pelo segundo. O que Mankiw propõe é que de acordo com a dimensão temporal macroeconômica - curto ou longo prazo — , um modelo se apresentará mais adequado em relação ao outro.

Os manuais de economia veiculam, segundo a terminologia kuhniana, o paradigma da ciência normal. Conforme afirma Kuhn, nos períodos de ciência normal nada de novo é proposto, os cientistas devem somente tratar de resolver os problemas propostos pelo paradigma dominante com o uso do instrumental fornecido.

A ciência normal não tem como objetivo trazer à tona novas espécies de fenômeno; na verdade, aqueles que não se ajustam aos limites do paradigma freqüentemente nem são vistos. Os cientistas também não estão constantemente procurando inventar novas teorias; freqüentemente mostram-se intolerantes com aquelas inventadas por outros. Em vez disso, a pesquisa científica normal está dirigida para a articulação daqueles fenômenos e teorias já fornecidos pelo paradigma. (Kuhn 2003, p.45)

Nos manuais o que se observa é um conjunto de instrumentos, de modelos teóricos, cada um deles adequado à investigação de uma parcela da realidade. O método utilizado para a construção desses modelos teóricos não é questionado, no máximo, como vimos, o autor os expõem, de maneira que o que se verifica é justamente o que foi acima definido como ciência normal. Por conseguinte, o paradigma dominante é apreendido pelos estudantes por intermédio de manuais que veiculam uma coleção de teorias. O economista deve aplicar essas teorias à realidade, devendo sua explicação necessariamente partir do referencial fornecido por tal paradigma. Esse aprendizado, no entanto, possui dois momentos, um consciente e um não imediatamente consciente. Ao entrar em contato com os modelos econômicos, o estudante aprende conscientemente o instrumental de análise da realidade - como o modelo clássico, por exemplo -, mas também apreende de forma não consciente um conjunto de valores veiculados por uma tradição científica. Nesse sentido, podemos dizer que as hipóteses fundamentais possuem um papel mais amplo que a simples estruturação de um modelo teórico do tipo hipotético-dedutivo. Os pressupostos do modelo podem revelar a visão de mundo veiculada por determinada tradição científica, ou seja, como é a realidade que os cientistas têm em mente quando fazem asserções acerca dos fenômenos econômicos.

Em seguida, faremos a exposição das hipóteses fundamentais do modelo keynesiano simples, que não deve ser confundido com as ideias originais de Keynes. Há uma tentativa de resgate dos postulados de Keynes por parte da escola pós-keynesiana, no entanto, para a análise à qual procederemos tomaremos o modelo keynesiano, conforme exposto nos manuais de economia, como forma de mantermos uma proximidade em relação aos objetivos iniciais de nossa exposição. Contudo, devemos sempre ter em mente que esta é uma leitura particular, neoclássica, dos postulados de Keynes.

Principia 18(2): 187-208 (2014). 
Assim como o modelo clássico simples, o modelo keynesiano simples também se estrutura de acordo com o modelo hipotético-dedutivo, possuindo três hipóteses fundamentais que se contrapõem às do modelo clássico, são elas: (i) princípio da demanda efetiva; (ii) moeda como um ativo; (iii) preços e salários são rígidos.

A hipótese de rigidez dos preços refere-se à dimensão temporal adotada pelo modelo keynesiano. Desta maneira, supõe-se que no curto prazo preços e salários são rígidos, podendo o produto estar abaixo ou acima do nível de pleno emprego, não havendo, como no mundo clássico, ajuste automático no mercado de trabalho.

A hipótese da neutralidade da moeda é criticada, passando a moeda a ser compreendida como um ativo desejado pelos agentes. Outra hipótese fundamental do modelo clássico que também é contestada refere-se à lei de Say. A função de reserva de valor da moeda é incompatível com a ideia de que a oferta gera sua própria demanda, pois se os agentes demandam moeda não apenas para realizar transações, mas também para se precaver com relação a um futuro incerto, esse entesouramento de recursos monetários pode causar um desajuste entre oferta e demanda no curto prazo.

Ao contrário da visão dos clássicos, e em oposição direta à lei de Say, a visão keynesiana indica que é a demanda efetiva que determina a oferta, posto que os empresários tomarão suas decisões acerca de quanto produzir a partir das expectativas acerca da demanda futura por seus produtos, comparando-a com os custos envolvidos em sua produção, caso o retorno seja satisfatório, os empresários decidirão investir. Essa decisão de investimento é tomada pelo empresário através da observação de duas curvas virtuais, a saber, uma de demanda esperada e outra de custos envolvidos no suprimento dessa demanda. Tal decisão será tomada a partir da comparação entre a eficiência marginal do capital e a taxa de juros. Sendo a eficiência marginal do capital a taxa de desconto que iguala o fluxo de receitas esperado ao custo do investimento, e sendo a taxa de juros a representação dos custos envolvidos na tomada de empréstimos ou o custo de oportunidade de imobilização de recursos produtivos, o empresário somente investirá se a eficiência marginal do capital for superior à taxa de juros (Lopes \& Vasconcellos 2000, p.114-6).

Ao decidir pelo investimento, o empresário contratará trabalhadores, que uma vez empregados receberão um salário, em parte convertido em consumo, o que representa um aumento na demanda efetiva. Tal aumento na demanda poderá gerar expectativas otimistas quanto à demanda futura, fazendo com que os empresários façam novos investimentos, contratando mais trabalhadores, aumentando a demanda efetiva e assim por diante. Gera-se, portanto, um ciclo virtuoso de crescimento econômico, em que a demanda (agregada) é o input que dispara esse ciclo através da influência positiva que exerce sobre as decisões de investimento. Por conseguinte, não há automatismo entre oferta e demanda, dependendo a oferta, em última instância, da demanda esperada, responsável pela decisão de investimento dos empresários.

Principia 18(2): 187-208 (2014). 
Assim, o princípio da demanda efetiva busca mostrar que a oferta não gera sua própria demanda, posto que sem a hipótese da neutralidade da moeda, a possibilidade de uma destinação diversa para a moeda que não seja a compra de bens está dada. Ou seja, no mundo keynesiano o entesouramento é possível, de maneira que o agente pode utilizar sua renda para comprar bens e serviços, bem como pode decidir guardar parte dessa renda como forma de se precaver com relação a eventos futuros. Se o que aumenta o emprego da economia é a expansão da capacidade produtiva, que somente pode ocorrer através do investimento, cuja decisão compete ao empresário e depende das expectativas relativas à demanda futura, decorre daí que o fator determinante do nível de produto no mundo keynesiano é a demanda (agregada). A possibilidade de crises de realização está dada no mundo keynesiano, já que pode haver insuficiência ou excesso de demanda efetiva, causando desemprego ou superemprego. Mais, no mundo keynesiano pode haver desemprego voluntário, pois como salários e preços são rígidos, não há ajustamento automático no mercado de trabalho, de modo que nem sempre a economia estará no nível de pleno emprego. Destarte, enquanto no modelo clássico a única razão para o desemprego era o desejo do indivíduo de não ofertar sua força de trabalho - desemprego voluntário —, no modelo keynesiano admite-se que o indivíduo pode desejar ofertar sua força de trabalho a qualquer preço, mas mesmo assim não encontrar emprego - desemprego involuntário.

Apesar das hipóteses do modelo keynesiano serem opostas aos pressupostos básicos do modelo clássico, pode-se classificar ambos sob o modelo hipotético-dedutivo de explicação científica, cuja concepção de lei científica do tipo covering-law encontra-se implicada nesse modelo. No entanto, a visão de mundo que os dois modelos veiculam é diferente. Enquanto no mundo clássico as crises não são possíveis, dada a lei de Say, e as pessoas somente não se empregam voluntariamente, no mundo keynesiano as crises são possíveis e o fato das pessoas não encontrarem emprego deixa de ser um fenômeno exclusivamente voluntário, trabalhadores podem não encontrar uma colocação no mercado de trabalho mesmo que aceitem um salário menor, ou seja, pode haver desemprego involuntário. Como vimos, no mundo clássico o desemprego involuntário é impossível, pois o equilíbrio ao nível do pleno emprego estava garantido através de um pressuposto do modelo, a flexibilidade de preços e salários, que assegurava um ajuste automático entre oferta e demanda por trabalho.

Portanto, a visão de mundo do modelo clássico é diversa da visão de mundo do modelo keynesiano, visto que suas hipóteses fundamentais produzem um desenho diverso da realidade. Tais hipóteses possuem ainda outro papel, o de delimitar o campo dos fenômenos que são reconhecidos e/ou permitidos no mundo, de maneira que é possível afirmar que os modelos teóricos anteriormente apresentados entretêm uma concepção de realidade que se limita ao paradigma que a define, ou seja, a realidade é composta de sistemas fechados. Essa asserção está de acordo com o tipo 
de lei científica do tipo covering-law, implicada em modelos hipotético-dedutivos, como o modelo clássico e o modelo keynesiano. Como veremos adiante, todo modelo teórico do tipo hipotético-dedutivo, cuja concepção de lei científica reside na ideia de lei de Hume, pressupõe não apenas sistemas fechados, mas também que estes estejam presentes em todos os lugares. ${ }^{5}$

Na seção seguinte nossa atenção voltar-se-á para a questão do critério de escolha entre teorias, na qual serão trazidas à luz as ideias de revolução científica de Kuhn, programa de pesquisa científico (PPC) de Lakatos, com suas implicações instrumentais.

\section{A possibilidade de confronto de visões de mundo concorrentes}

Os manuais de macroeconomia apresentam os modelos keynesiano e clássico como casos particulares do modelo IS-LM, muito embora o modelo IS-LM seja de origem keynesiana, já que adota, em sua versão mais simples, as hipóteses fundamentais do modelo keynesiano simples. ${ }^{6}$ De acordo com essa leitura, a contribuição de Keynes teria apenas o caráter de contribuição à ampliação do poder preditivo e explanatório da tradição neoclássica, não se apresentando como uma tradição concorrente, mas complementar ao já estabelecido programa de pesquisa neoclássico. Em termos lakatosianos, nos é permitido afirmar que as ideias keynesianas, tal qual apresentadas no modelo IS-LM, teriam representado um episódio de alargamento do cinturão protetor do PPC neoclássico, o qualificando como um PPC teórica e empiricamente progressivo. A tradição neoclássica seria assim caracterizada como um PCC progressivo, por ser capaz de alargar o espectro de fenômenos previstos e corroborados empiricamente pelas suas teorias componentes.

Entretanto, essa é uma das leituras de Keynes, conhecida como síntese neoclássica, elaborada por Hicks a partir da Teoria Geral, originalmente publicada por Keynes em 1936. ${ }^{7}$ Como anteriormente indicado, outra corrente de pensamento, os póskeynesianos, vindicam para si uma interpretação alternativa das ideias de Keynes, afirmando ainda que o problema da economia clássica residia em sua concepção de mundo, não em sua construção interna, e é nesse sentido que a revolução keynesiana pode ser entendida como uma revolução paradigmática (Carvalho 1989, p.179).

A crítica à teoria clássica não é, assim, imanente, mas externa. Não se busca formas alternativas de dar sentido à construção ortodoxa ou de induzir qualificações a seus postulados, mas, sim, de estabelecer visão paralela, autônoma, concorrente à escola ortodoxa. (Carvalho 1989, p.180)

Pode-se dizer que os pós-keynesianos sustentam que as ideias de Keynes foram responsáveis por uma revolução paradigmática no sentido kuhniano, negando a leitura hicksiana, que entende as concepções teóricas de Keynes como uma contribui- 
ção ao programa de pesquisa neoclássico, inaugurando mais um compartimento no interior da ciência econômica, a macroeconomia. ${ }^{8}$ Pode-se dizer que a compreensão do crescimento do conhecimento através da agregação de novas teorias ao programa de pesquisa estabelecido - a ideia de PPC progressivo - remete diretamente ao período de ciência normal descrito por Kuhn. Contra esse entendimento do papel das concepções de Keynes apresentam-se os pós-keynesianos.

Segundo os pós-keynesianos, os postulados de Keynes não são apenas a base de mais um modelo alternativo de explicação dos fenômenos da realidade, constituem antes a proposição de uma nova visão de mundo, de um novo paradigma. Segundo Kuhn (2003), uma revolução paradigmática ocorre sempre que há o surgimento de anomalias, eventos diversos daqueles previstos pelo paradigma, e este se mostra incapaz de solucionar tais anomalias no âmbito das teorias compartilhadas pela comunidade científica. Inicia-se um período de ciência extraordinária, em que diversos paradigmas concorrentes apresentam explicações alternativas para o novo fenômeno, até que um deles possa emergir como novo paradigma dominante.

Na década de 1930 a economia mundial vivia uma intensa crise econômica, em que o desemprego apresentava-se como o problema mais imediato. No âmbito das teorias econômicas ortodoxas, uma explicação para os fenômenos desse período histórico não pôde ser encontrada. Os postulados de Keynes podem assim ser compreendidos como a proposta de um novo paradigma, sendo suas ideias amplamente adotadas nos anos que se seguiram, muito embora políticas de estímulo à demanda efetiva tenham sido implementas antes da publicação da Teoria Geral, em 1936. A partir do critério kuhniano de escolha entre teorias, a opção entre o modelo clássico e o keynesiano pode ser explicado com base na fé da comunidade científica num modelo ou no outro. Já segundo Lakatos, a escolha entre esses modelos estaria ancorada em sua capacidade explicativa e preditiva.

Uma leitura kuhniana da alternância entre paradigmas insere a importante ideia de que todo conhecimento é historicamente fundado, de modo que os eventos da realidade produzem mudanças teóricas substantivas na medida em que se apresentam como anomalias insolúveis ao paradigma dominante. Entretanto, não somos capazes de explicar racionalmente, a partir de uma ótica kuhniana, o porquê de determinado paradigma ter sido escolhido em detrimento dos demais. Podemos atribuir tal incapacidade de explicação à ideia de paradigma enquanto um conjunto irrefutável de hipóteses fundamentais, em que a emergência de um novo paradigma somente pode ser atribuída à fé da comunidade científica nesse novo paradigma dominante. Tampouco podemos nos apoiar na concepção lakatosiana de crescimento do conhecimento, uma vez que um PPC progressivo consiste na expressão de um período de ciência normal, em que não há a colocação de novos problemas, mas apenas a solução dos já existentes, propostos pelo núcleo rígido do PCC. ${ }^{9}$

As filosofias da ciência de Kuhn e de Lakatos possuem o mérito de afirmar o cará-

Principia 18(2): 187-208 (2014). 
ter histórico e social do conhecimento científico, mas parece que não são capazes de explicar, a partir de bases racionais, a dinâmica entre teorias. De acordo com Kuhn um novo paradigma emerge a partir de um critério de fé dos cientistas, e segundo Lakatos o que explica a superioridade de uma tradição científica frente às demais é a sua capacidade preditiva. Muito embora Lakatos seja um crítico do instrumentalismo, suas asserções acerca da evolução do conhecimento científico acabam por abrir espaço para que sejam elaboradas justificativas a favor de critérios instrumentais de escolha e construção científica.

A defesa do instrumentalismo enquanto critério de escolha entre teorias é sugerida por Friedman (1981). ${ }^{10}$ Nesse artigo, inicialmente, é feita uma distinção entre ciência positiva - asserções sobre o que é - e ciência normativa - afirmações concernentes ao que deve ser —, conforme teria proposto Neville Keynes (Friedman 1981, p.163). A ciência normativa poderia apenas apontar o que os sujeitos avaliam como desejável, mas não possuiria caráter científico, o qual somente poderia ser atribuído à ciência positiva. Precisamente nesse sentido é que Friedman desenvolve um argumento a favor da Economia como uma ciência essencialmente positiva. A conexão com o positivismo lógico é visível.

Ao afastar os elementos normativos, seria possível evitar que a ciência fosse permeada pela visão de mundo do sujeito cognoscente, somente deste modo seria possível alcançar uma ciência objetiva, portanto, positiva na concepção de Friedman. Para Friedman, ciência positiva significa ciência axiologicamente neutra, desconectando assim a ideia de objetividade da concepção de verdade. Deste modo, a ciência positiva não pretenderia realizar asserções ontológicas, constituindo-se apenas em instrumento de captura de regularidades empíricas, presentes no mundo tal como ele é, sendo o critério da boa teoria sustentado por sua capacidade de produzir previsões acuradas acerca dos eventos da realidade. Importante notar que esse critério da boa teoria é compatível com a ideia de PCC progressivo, conforme sugerida por Lakatos.

Segundo Friedman (1981), as teorias científicas possuiriam dois componentes: linguagem e hipóteses substantivas. Ademais, as hipóteses substantivas seriam em parte implicações (previsões) e em parte pressupostos. As implicações, sendo previsões, poderiam ser validadas ou não empiricamente. Já os pressupostos seriam abstrações de elementos da realidade, interditando seu julgamento quanto ao seu realismo. De acordo com Friedman, por constituírem uma abstração da realidade, os pressupostos não podem ser realistas. Ao abstrair um elemento da realidade, o pressuposto não é capaz de capturar as conexões reais presentes no mundo, de modo que acaba por desfazer a configuração original da realidade quando busca apreendê-la conceitualmente. Por conseguinte, os pressupostos poderiam ser apenas representações simplificadas dos elementos da realidade. Uma teoria econômica, nessa concepção instrumentalista, não poderia jamais capturar todas as conexões da realidade econômica, uma vez que acabaria reproduzindo a realidade num imenso e impro- 
vável modelo que se configuraria como uma cópia da realidade. Nas palavras de Friedman:

\begin{abstract}
Uma teoria ou os seus 'pressupostos' não podem ser cabalmente 'realistas', no sentido descritivo imediato, que tão frequentemente se atribui ao termo. Uma teoria completamente 'realista' do mercado do trigo teria de incluir não apenas as condições diretamente subjacentes à oferta e à demanda de trigo, como, ainda, indicações relativas à moeda ou aos instrumentos de crédito usados nos pagamentos; teria de incluir dados a respeito dos comerciantes de trigo, cor dos olhos e dos cabelos de cada comerciante, os seus antepassados, a sua educação, as pessoas da família, seus respectivos antecedentes e sua educação, e assim por diante; teria de incluir informes a respeito do tipo de solo em que o cereal foi cultivado, de suas características físicas e químicas, do estado geral do tempo na época de desenvolvimento das plantas, dos traços típicos do pessoal encarregado de cuidar da fazenda e do consumidor que, afinal, utilizará os grãos; e assim por diante, indefinidamente (Friedman 1981, p.189-90).
\end{abstract}

Se o mundo é infinitamente complexo e os modelos teóricos são meros instrumentos de captura de eventos desse mundo, não haveria, nessa concepção instrumentalista da ciência, como obter um conhecimento objetivo do mundo. Importante notar que conhecimento objetivo, na concepção instrumentalista, implica conhecimento absoluto. A identificação, ainda que implícita, de conhecimento objetivo com conhecimento absoluto interdita a possibilidade de construção de teorias que capturem objetivamente os eventos do mundo, restando como critério de escolha entre teorias a sua capacidade preditiva. Deste modo, as hipóteses de um modelo teórico só estariam habilitadas a reproduzir de forma simplificada a realidade, somente assim a ciência seria útil.

Em defesa do instrumentalismo, ${ }^{11}$ Reiss (2012) sustenta que a verdade não possui um papel importante para o instrumentalista, uma vez que "existem muitas verdades inúteis, assim como existem muitas falsidades úteis."12 (Reiss 2012, p.365) Mas a ciência não deveria produzir conhecimentos verdadeiros sobre o mundo? Mesmo os instrumentalistas responderiam afirmativamente a essa questão caso não considerassem impossível a obtenção de um conhecimento verdadeiro sobre o mundo. Essa postura é compreensível, uma vez que o instrumentalismo identifica verdade, que é diferente de conhecimento objetivo, com verdade absoluta. Naturalmente, a apreensão de uma verdade absoluta sobre o mundo, além de impossível, colocaria um ponto final no empreendimento científico.

Ademais, o instrumentalismo identifica objetividade com um conhecimento axiologicamente neutro, deixando de lado o consenso que se formou a partir da falência do projeto lógico-positivista, a saber, não é possível eliminar a metafísica, os valores, da teoria científica. Nesse sentido, foi preciso reconhecer que toda teoria pressupõe

Principia 18(2): 187-208 (2014). 
uma visão de mundo, uma ontologia, ou seja, não é possível construir uma ciência axiologicamente neutra. Ainda que implicitamente, toda teoria carrega em si e consigo uma visão de mundo. Portanto, mesmo a ciência positiva, defendida pelos instrumentalistas, traz consigo uma visão de mundo.

Os instrumentalistas poderiam argumentar que nada disso faz sentido ou é significante para a ciência, uma vez que a ciência deve se limitar a produzir teorias úteis, em lugar de verdades inúteis, como sugeriu Reiss (2012). Mas se a ciência está, segundo a concepção instrumentalista, fadada a produzir apenas teorias úteis, seria lícito questionar para quê e para quem seria essa ciência útil. Se toda teoria carrega uma visão de mundo, ainda que implicitamente, qual visão de mundo as teorias instrumentalistas, ditas axiologicamente neutras, estariam carregando? Do ponto de vista filosófico não é difícil identificar o instrumentalismo com uma ontologia positivista, uma vez que a objetividade instrumentalista implica uma descrição infindável dos elementos empíricos que participam do fenômeno observado, além de negar a metafísica na construção teórica quando sugere uma ciência positiva, axiologicamente neutra. Além disso, teorias estruturadas conforme o modelo $H-D$ contém em si uma circularidade no que concerne ao seu teste empírico.

(...) se a teoria determina a priori como é a configuração do mundo e, com isso, determina igualmente aquilo que é relevante (dados, eventos, objetos, relações) e ao mesmo tempo prescreve os critérios de corroboração empírica, parece evidente que se está então diante de uma flagrante circularidade. (Duayer, Medeiros e Painceira, 2001, p.759)

Para além da questão dessas teorias pretensamente axiologicamente neutras já nascerem validadas de antemão, o principal problema da negação da ontologia é que ela não é um componente eliminável do discurso científico. Uma ciência positiva nos moldes do instrumentalismo proposto por Friedman não é possível. A principal implicação da tentativa de construção de uma ciência axiologicamente neutra é a veiculação de uma visão de mundo que não é questionada, uma vez que para o instrumentalista ela não estaria e/ou não deveria estar presente na ciência positiva. Mesmo que considerássemos que a Economia, neoclássica ou ortodoxa, consegue construir teorias bem próximas do ideal instrumentalista, produzindo teorias úteis, seriam essas teorias úteis à sociedade? A economia neoclássica ocupa o mainstream econômico há décadas, produzindo os mais variados modelos. Contudo, questões como o subdesenvolvimento e as crises do sistema capitalista continuam se repetindo sem solução, modelo após modelo. Mais uma vez seria lícito questionar se a ciência econômica neoclássica está produzindo teorias úteis à sociedade, uma vez que as prescrições instrumentalistas as desabilitaram da busca de um conhecimento objetivo, verdadeiro, acerca do mundo econômico.

Contra o instrumentalismo se opõe o realismo crítico, ${ }^{13}$ que afirma que a realidade dos pressupostos é fundamental não apenas na construção teórica, mas tam- 
bém na ocasião da escolha entre teorias. ${ }^{14}$ Lawson afirma que toda teoria pressupõe uma ontologia, e apenas o reconhecimento dessa dimensão das teorias científicas pode fornecer bases racionais para o julgamento entre teorias. ${ }^{15}$ A proposta principal dessa corrente filosófica, que surge na década de 1970 a partir das ideias de Bhaskar (1997), consiste na restauração da ontologia. O realismo crítico busca indicar não apenas um novo método de construção teórica, mas também, a partir daí, lançar as bases para uma racionalidade julgamental.

A visão de mundo, ou ontologia, possui um papel fundamental no confronto entre teorias, pois é a partir da explicitação da visão de mundo pressuposta por uma teoria científica que se pode compará-la com outras teorias e suas respectivas ontologias, para que possamos, enfim, confrontá-las com a realidade mesma, instância que nos permitirá escolher racionalmente aquela teoria que produz uma visão de mundo mais adequada a essa realidade social moldada historicamente. Assim, a diferença fundamental entre o realismo crítico e a filosofia de Kuhn e Lakatos é a capacidade da primeira em fornecer um critério racional de escolha entre teorias concorrentes. Vejamos, brevemente, como o realismo crítico fornece as bases para a construção de teorias objetivas, não absolutas, acerca do mundo, além de permitir um racionalismo julgamental no que concerne à escolha entre teorias concorrentes.

Lawson (1997) identifica o modelo H-D, e as leis do tipo covering-law nele implicadas, com um conjunto de métodos denominado dedutivismo, analisando a adequação desses métodos inicialmente à ciência natural e posteriormente à ciência social. Conforme visto anteriormente, o termo dedutivismo significa uma modalidade de lei científica comprometida com padrões de eventos do tipo "sempre que evento $x$, então evento $y$ " (Lawson 1997, p.17). Ou seja, perfeitamente identificável com a modalidade de construção teórica presente nos modelos clássico e keynesiano, conforme delineados nos manuais de economia, além de compatível com uma concepção instrumental de ciência.

O principal problema do dedutivismo é que as conjunções constantes de eventos do tipo "sempre que evento $x$, então evento $y$ " somente estão presentes em sistemas fechados. Deste modo, para que seja possível a existência de leis dedutivistas no mundo, este deveria ser povoado de sistemas fechados, nos quais seria possível prever todos os eventos futuros, uma vez que o futuro também estaria dado no âmbito desses sistemas fechados. Ademais, se a lei científica se resume a uma imensa coleção de eventos empíricos, a realidade pressuposta pelo dedutivismo é não apenas composta de sistemas fechados, mas também de eventos atomísticos, que não guardam relações entre si, apenas correlações. Assim sendo, as leis dedutivistas somente estariam presentes no âmbito dos fechamentos artificialmente produzidos nos laboratórios. Diante dos avanços da ciência natural e da presença de sistemas abertos no mundo, somos levados a questionar a aplicabilidade do dedutivismo enquanto método de investigação científica.

Principia 18(2): 187-208 (2014). 
Destarte, Lawson $(1997,2003)$ sustenta que o dedutivismo não está habilitado a explicar a prática efetiva da ciência natural. Ademais, afirma que os fechamentos artificiais produzidos em laboratório são realizados no intuito de desvendar leis e mecanismos que não podem ser empiricamente verificáveis, mas podem ser acessados e conhecidos a partir dos efeitos que produzem. Bhaskar (1997) exemplifica essa questão com a atração de pregos por um ímã, em que os pregos e o ímã são objetos empíricos, o evento dos pregos sendo atraídos pelo ímã pode ser empiricamente observado, mas o magnetismo, que causa esse evento, não pode ser capturado pelos cinco sentidos. Deste modo, o magnetismo somente pode ser conhecido através dos efeitos que produz. Bhaskar (1997) e Lawson $(1997,2003)$ sugerem então uma estratificação da realidade em empírico, efetivo e real. Como a concepção de ciência dedutivista, incluída a instrumentalista, se esgota na esfera empírica é compreensível seu ceticismo quanto à possibilidade de se conhecer um mundo povoado de eventos atomísticos sem relação alguma entre si. O magnetismo seria, portanto, uma verdade inútil à ciência, enquanto as correlações entre pregos e ímãs seriam as falsidades úteis que deveriam ser catalogadas pela ciência positiva.

Resta delinear, ainda que brevemente, o argumento de Lawson (1997) acerca da inteligibilidade da ciência social. ${ }^{16}$ Um argumento similar ao da ciência natural é utilizado para compreender a possibilidade de conhecimento na ciência social, contudo, devemos reconhecer que o objeto da ciência social é distinto do objeto da ciência natural. O objeto de estudo da ciência é denominado dimensão intransitiva do conhecimento, uma vez que independe, ao menos em parte, das teorias (dimensão transitiva do conhecimento) elaboradas para compreendê-lo. A principal distinção entre o objeto da ciência social em relação ao objeto da ciência natural remete ao fato que o intransitivo social pode ser permeado pelas concepções (transitivo) que dele entretemos, enquanto o intransitivo natural não pode ser permeado por nossas concepções a seu respeito. Nesse sentido, as instituições se reproduzem e se modificam ao longo do tempo por intermédio das concepções e das ações humana, ${ }^{17}$ a gravidade continua operando independentemente do que dela pensamos.

No intuito de avaliar a adequação do dedutivismo à ciência social, Lawson (1997) analisa o estatuto da escolha humana, um tema bastante caro à economia neoclássica. $\mathrm{O}$ autor conclui que a condição de possibilidade da escolha humana pressupõe não apenas a existência de sistemas abertos, mas também que os agentes possuam alguma ideia do que estão fazendo e o que pretendem com sua ação, em outras palavras, o agir humano é intencional (Lawson, 1997, p.30). A intencionalidade, por sua vez, pressupõe estruturas relativamente duradouras e se essas estruturas dependem da ação humana para existir, então, essas estruturas são sociais. As estruturas sociais possuem, assim como as estruturas naturais, uma dimensão não empiricamente verificável, na qual estão presentes leis e mecanismos causadores do curso efetivo de eventos.

Principia 18(2): 187-208 (2014). 
Essa análise da adequação do dedutivismo à ciência natural e à ciência social é um exemplo do método retrodutivo sugerido por Lawson (1997), do qual se parte de uma esfera empírico-efetiva da realidade (atividade experimental, escolha humana) para a esfera real (leis e mecanismos naturais, leis e mecanismos sociais). ${ }^{18}$ O método retrodutivo pode ser visto, portanto, como um método alternativo ao dedutivismo, presente no instrumentalismo, sendo capaz de fornecer inteligibilidade à prática efetiva da ciência natural, bem como da ciência social. Ademais, a distinção entre uma dimensão transitiva (teoria) e uma dimensão intransitiva (objeto) do conhecimento, permite um racionalismo julgamental quando duas teorias são comparadas, uma vez que não há circularidade no julgamento de teorias diversas se existe um objeto relativamente duradouro com o qual essas teorias podem ser comparadas.

Se o positivismo lógico falhou por não reconhecer a dimensão transitiva do conhecimento em sua batalha contra a metafísica, Kuhn e Lakatos não puderam estabelecer critérios racionais de escolha entre teorias por desconsiderar a dimensão intransitiva do conhecimento. O resultado das inconsistências desses dois projetos metodológicos foi o total ceticismo quanto à possibilidade de se conhecer o mundo, presente no instrumentalismo. Por fim, o realismo crítico não defende a busca de um conhecimento objetivo, não absoluto, simplesmente por ser otimista em relação à possibilidade de construção de conhecimentos verdadeiros acerca do mundo. $\mathrm{O}$ realismo crítico sustenta a possibilidade da obtenção um conhecimento objetivo a partir de uma ontologia crítico-realista e de um método retrodutivo de investigação científica, cuja inteligibilidade pode ser demonstrada através da análise da atividade experimental, no âmbito da ciência natural, e da escolha humana, no âmbito da ciência social. Destarte, a condição de possibilidade de uma ciência objetiva é sustentada a partir do próprio objeto de estudo da ciência.

\section{Conclusão}

Foram apresentados, a partir de dois modelos macroeconômicos de determinação da renda - modelo clássico e modelo keynesiano - , os conceitos de modelo hipotéticodedutivo, lei científica do tipo covering-law, bem como o conceito de paradigma kuhniano, análogo à ideia de núcleo rígido lakatosiano. Ambos os conceitos, podem ser entendidos como a visão de mundo - ou ontologia - pressuposta pelas teorias científicas, implícita nas hipóteses fundamentais desses modelos teóricos.

Como principais desdobramentos do projeto lógico-positivista emergiram a ideia de teoria científica como modelo hipotético-dedutivo, bem como a admissão de que um conhecimento objetivo é inalcançável, justificando, assim, a construção de modelos teóricos cujas hipóteses podem ser irrealistas. Tal descrição acerca do empre-

Principia 18(2): 187-208 (2014). 
endimento científico encontra sua maior expressão no instrumentalismo. Lakatos, apesar de crítico do instrumentalismo, produz uma filosofia da ciência que permite uma justificação do discurso científico a favor do instrumentalismo, na medida em que o critério que diferencia um PCC dos demais é sua capacidade preditiva, critério este essencialmente instrumental. Kuhn, ao atribuir a escolha de um novo paradigma para a nova ciência normal à fé da comunidade científica, incorre, explicitamente, na admissão de que não há critério racional que explique uma mudança paradigmática.

Identificamos a crise dos anos 1930 como um evento que colocou novos problemas à teoria econômica ortodoxa, que encontraram explicação na Teoria Geral de Keynes (1997 [1936]). Contudo, vimos que não existe uma leitura única da obra de Keynes. Enquanto numa perspectiva hicksiana as ideias de Keynes são interpretadas à luz do modelo keynesiano simples, no qual representam antes uma contribuição que uma crítica à tradição neoclássica, na concepção pós-keynesiana as ideias de Keynes são uma crítica ao pensamento clássico e neoclássico, fornecendo uma nova visão de mundo.

Mesmo que se entenda a teoria de Keynes como uma contribuição ao PPC neoclássico ou como um novo paradigma, precisamos entender por que ela foi colocada, criticamente ou não, ao lado das demais teorias que buscavam explicar os fenômenos econômicos. Nesse ponto, não podemos negligenciar o fato da interpretação da realidade proposta por Keynes ter se apresentado como a teoria que, em sua época, foi capaz de capturar, de modo mais adequado, os fenômenos da realidade. Nesse sentido, pode-se afirmar que a visão de mundo veiculada pela teoria de Keynes teve, mesmo que de forma pouca explícita, um papel relevante quanto à sua adoção enquanto descrição do mundo. Naturalmente, Keynes não foi um crítico radical da teoria e da realidade econômica, como o fora Marx, o que talvez explique o fato de suas ideias terem sido tão prontamente apropriadas pelo programa de pesquisa neoclássico, cada vez mais incapaz, a essa época, de dar conta dos fenômenos da realidade.

Numa perspectiva kuhniana, poderíamos entender que os debates teóricos da década de 1930 foram, ao menos a princípio, um período de revolução paradigmática, em que a teoria ortodoxa foi desafiada pela Teoria Geral de Keynes. Contudo, apenas um ano após a publicação da Teoria Geral, Hicks sugere uma leitura dessa obra de Keynes que a coloca como um caso particular de uma teoria que se propunha mais geral. Assim, a teoria de Keynes acabou sendo assimilada, no âmbito do modelo ISLM, como parte do programa de pesquisa neoclássico, não como um programa de pesquisa alternativo como sugeriram os pós-keynesianos.

Destarte, no âmbito dos critérios de escolha teórica lakatosianos, poder-se-ia entender os debates em torno da Teoria Geral e da crise da década de 1930 como um momento de alargamento do cinturão protetor do programa de pesquisa neoclássico, em que a leitura hicksiana da obra de Keynes teria sido eleita a vencedora 
justamente por ser capaz de fornecer teorias com maior poder preditivo ao programa de pesquisa neoclássico. Do mesmo modo, a escolha entre o modelo clássico e o modelo keynesiano não deveria, segundo um critério instrumental, remeter ao realismo dos seus respectivos pressupostos, mas sim à capacidade preditiva da teoria como um todo. Entretanto, vimos que os pressupostos teóricos veiculam uma visão de mundo, ou ontologia, que não pode ser negligenciada sob pena de recorrentes fracassos teóricos quanto à compreensão e explicação do mundo pela teoria científica. Essa negligência ontológica é denunciada por Lawson e pelo realismo crítico. As consequências imediatas dessa negligência ontológica podem ser observadas nas tentativas fracassadas da teoria econômica ortodoxa em responder de forma adequada e objetiva às questões postas pela realidade econômica. Problemas como a pobreza, o subdesenvolvimento, a violência, dentre outros, são muito modelados e mensurados, mas as causas e as possíveis soluções desses problemas não recebem resposta satisfatória no âmbito dos modelos teóricos que fazem parte do programa de pesquisa neoclássico.

\section{Referências}

Bhaskar, R. 1997. A Realist Theory of Science. London: Verso. 1998. Societies. In: M. Archer et al. (ed.) Critical Realism: essential readings. Londres: Routlegde, p.206-57.

Caldwell, B. 1982. Beyond positivism: economic methodology in the twentieth century. Londres: George Allen \& Unwin.

Carvalho, F; Cardin, J. 1989. Fundamentos da Escola Pós-Keynesiana: a Teoria de uma Economia Monetária. In: E. Amadeo et alii. (org.) Ensaios sobre Economia Política Moderna: Teoria e História do Pensamento Econômico. São Paulo: Marco Zero.

Cavalcante, C. M. 2005. Ciência e Filosofia: uma discussão acerca da possibilidade do conhecimento objetivo. Niterói: [s.n.].

Combat, F. A.; Corrêa, H. F. S.; Carmo, R. M.; Santos, T. V. F. 2004. Para além do empírico: uma crítica ao movimento pós-autista. Niterói: EdUFF.

Duayer, M. 2001. Economia: Ciência à Frete? ENCONTRO NACIONAL DE ECONOMIA POLÍTICA, 6. São Paulo. Disponível em: www.sep.org.br.

Duayer, M.; Medeiros, J. L.; Paincera, J. P. 2001. A miséria do instrumentalismo na tradição neoclássica. Estudos Econômicos 15(4): 723-83.

Friedman, M. 1981. A Metodologia da Economia Positiva. Edições Multiplic, v. 1, n.3, fevereiro.

Fucidji, J. R. 2006. O Realismo Crítico e seus oponentes. In: ENCONTRO NACIONAL DE ECONOMIA POLÍTICA 11., Vitória.

Hicks, J. R. 1937. Mr. Keynes and the "Classics": a suggested interpretation. Econometrica 5(2): 147-59.

Keynes, J. M. 1997[1936]. The General Theory of Employment, Interest, and Money. New York: Prometheus Books.

Principia 18(2): 187-208 (2014). 
Kuhn, T. S. 2003. A Estrutura das Revoluções Científicas. 7ª̣ ed. São Paulo: Editora Perspectiva. Lawson, T. 1997. Economics and Reality. London: Routledge.

- 2003. Reorienting Economics. London: Routledge.

2015. What is an institution? In: S. Pratten. Social Ontology and Modern Economics. London: Routledge.

Lisboa, M. B. 1998. A Miséria da Crítica Heterodoxa - Segunda Parte: Método e Equilíbrio na Tradição Neoclássica. Revista de Economia Contemporânea 3: 113-51.

Mankiw, N. G. 1998. Macroeconomia. $3^{a}$ ed. Rio de Janeiro: LTC.

- 1999. Introdução à Economia: princípios de micro e macroeconomia. Rio de Janeiro: Campus.

Mansor, M. 2010. A Matematização das Ciências Sociais. In: XV ENCONTRO NACIONAL DE ECONOMIA POLÍTICA. São Luiz, Maranhão, pp.1-4 jun.

Reiss, J. 2012. Idealization and the aims of economics: three cheers for instrumentalism. Economics and Philosophy 28(3): 363-83.

Rossetti, J. P. 2000. Introdução à Economia. 18ª ed. São Paulo: Atlas.

Carolina Miranda Cavalcante Faculdade Nacional de Direito (FND) Universidade Federal do Rio de Janeiro (UFRJ)

Rio de Janeiro, BRASIL cmcavalcante@direito.ufrj.br

Resumo. Nesse artigo, procuro ilustrar alguns conceitos importantes de filosofia da ciência através da exposição de dois modelos macroeconômicos bastante simples, o clássico e o keynesiano, apresentados em cursos introdutórios de macroeconomia. Conceitos trabalhados em filosofia da ciência como o modelo hipotético-dedutivo, a tese da simetria, a ideia de paradigma kuhniano, o programa de pesquisa científico lakatosiano, bem como os propostos por Lawson no campo do realismo crítico, são buscados e identificados nesses modelos macroeconômicos como forma de mostrar que o estudo da metodologia é fundamental para a boa compreensão das teorias científicas — as matérias-primas da ciência social.

Palavras-chave: Modelo hipotético-dedutivo; modelos macroeconômicos; relativismo; instrumentalismo; realismo crítico.

\section{Notas}

${ }^{1}$ Para uma discussão mais detalhada acerca da profissão do economista ver Duayer (2001).

${ }^{2}$ By the above account, the formal structure of a theory is nothing more than of a mechanical calculus, or a hypothetical-deductive system. A theory contains axioms, or primitive sentences, and theorems, or derivative statements. The axioms may refer to either observables or theoretical entities. (Caldwell 1982, p.25)

${ }^{3}$ Desde o manifesto pós-autista, publicado por estudantes franceses no ano de 2000, uma grande discussão tem sido travada acerca da matematização e excessiva modelação em Economia. Esse debate pode ser acompanhado no site do movimento - www.paecon.net. No

Principia 18(2): 187-208 (2014). 
Brasil, tal debate ganha espaço por intermédio de uma publicação dos graduandos em Economia da USP - Informação Assimétrica. Para uma apreciação crítica do movimento pósautista ver ainda Combat; Corrêa; Carmo; Santos (2004).

${ }^{4}$ Sobre a concepção de ciência instrumental ver Friedman (1981).

${ }^{5}$ Para mais sobre a ideia de sistemas fechados implicada no modelo hipotético dedutivo e a idéia de lei científica como lei de Hume ver Lawson (1997).

${ }^{6}$ Importante notar que o modelo keynesiano simples não é uma leitura "pura" da obra de Keynes, mas sim uma apropriação sob a forma do que ficaria conhecido como o modelo IS-LM ou síntese neoclássica.

${ }^{7}$ As ideias de Keynes foram inicialmente abarcadas no âmbito das curvas IS-LM no artigo "Mr. Keynes and the 'Classics': a suggested interpretation", de Hicks (1937), publicado um ano depois da "Teoria Geral" de Keynes.

${ }^{8}$ Importante assinalar que não estamos afirmando que os pós-keynesianos adotam uma leitura kuhniana do desenvolvimento do conhecimento científico.

${ }^{9} \mathrm{O}$ conceito de núcleo rígido é análogo à ideia de paradigma, ou seja, é a visão de mundo, ou ontologia, veiculada por determinada tradição científica.

${ }^{10}$ Esse artigo de Milton Friedman foi originalmente publicado em 1953 sob o título "The Methodology of Positive Economics". Utilizo aqui uma versão em português publicada em 1981 sob o título "A Metodologia da Economia Positiva".

${ }^{11}$ Lisboa (1998) defende um conjunto de métodos que garantiria o caráter científico à Economia, como a ideia de PPC lakatosiano, falsificacionismo popperiano, bem como uma concepção instrumental de ciência.

12 Truth plays a much attenuated role in this image of Science, if any — for there are many useless truths, just as there are many useful falsehoods. (Reiss 2012, p.365)

13 Para uma discussão mais detalhada sobre as querelas entre instrumentalismo e realismo ver Cavalcante (2005). Para um debate acerca do espaço da matemática na construção teórica em Economia, remeto o leitor para o trabalho de Mansor (2010).

${ }^{14}$ Para as diversas modalidades de realismo e suas diferenças em relação ao realismo crítico, remeto o leitor para Fucidji (2006).

15 O arcabouço teórico do realismo crítico aqui proposto se baseia em Lawson (1997, 2003, 2015).

${ }^{16}$ Para uma discussão sobre as propriedades ontológicas da sociedade remeto o leitor ao artigo de Bhaskar (1998).

${ }^{17}$ Para uma compreensão das instituições a partir do realismo crítico, ver Lawson (2015).

${ }^{18}$ Importante notar que a estratificação da realidade não implica que as esferas empírica e efetiva sejam menos reais que a esfera real.

Principia 18(2): 187-208 (2014). 